\title{
CONE-BEAM COMPUTED TOMOGRAPHY VERSUS DIGITAL ORTHOPANTOMOGRAPHY IN TREATMENT PLANNING FOR MANDIBULAR DENTAL IMPLANTS
}

\author{
Tareq M. Albelbeisi ${ }^{\prime}$, Ahmed R Khtob ${ }^{2}$, Nagy E Hassan²
}

\begin{abstract}
INTRODUCTION: successful implant treatment depends on efficient planning. This should include information on height, width, morphology and density of the bone, as well as identification and location of anatomical landmarks in imaging exams.

OBJECTIVES: to investigate the impact of cone-beam computed tomography on implant planning and on prediction of final implant size. MATERIALS AND METHODS: overall, 17 implant were placed in the posterior mandible of ten patients with age ranging between (2550) years of both sexes. The patients were referred for pre surgical images. Initial planning of implant length and width was assessed based on panoramic radiograph exam, and final planning on cone-beam computed tomography exam to complement diagnosis. The actual dimensions of the implants placed during surgery were compared with those obtained during initial and final planning.

RESULTS: ten patients were selected, 4 males and 6 females and age ranged between (25-50) years. The study included 17 implants. Agreement in implant length was 58.8\% between initial and final planning, and correct prediction of the actual implant length was $58.8 \%$ and $100 \%$, using panoramic radiograph and cone-beam computed tomography exams, respectively. Agreement in implant width assessment ranged from $64.7 \%$ to $100 \%$. A paired comparison of the frequency of changes between initial or final planning and implant placement (paired t-test) showed greater frequency of changes in initial planning for implant length $(p<0.056)$, but not for implant width $(p=0.342)$.
\end{abstract}

CONCLUSIONS: it was concluded that cone-beam computed tomography improves the ability of predicting the actual implant length and reduces inaccuracy in surgical dental implant planning.

KEYWORDS: dental implant, radiography, panoramic, cone-beam computed tomography

1- B.D.S. Faculty of Dentistry, October 6 University.

2- Professor of Oral \& Maxillofacial Surgery Department, Faculty of Dentistry, Alexandria University.

\section{INTRODUCTION}

Alongside the technological development in implant manufacturing is a comparative development in the radiographic modalities which are essential before any implant procedure. The radiographic techniques perceived noticeable progress over the last decade especially with the development of digital radiographs and cone-beam computed tomography (1).

Before the late $1980 \mathrm{~s}$, conventional radiographic techniques like intraoral, cephalometric and panoramic images were accepted as standard methods (2). However, improvements in sectional imaging techniques led to the recommended use of tomographic methods to investigate potential implant sites. The American Academy of Oral and Maxillofacial Surgery recently recommended CBCT as the best option (3).

Implant placement has now become part of the everyday dental practice. Yet, more challenging than the implant placement procedure remains the proper preoperative planning preceding the surgery. The goal of preoperative planning in dental implantology is to enable the placement of implants of optimum number and size in the most favorable position in order to provide adequate masticatory, esthetic, and phonetic function $(4,5)$.

In addition, preoperative planning must encompass radiographic assessment of the proposed implant sites. The pre surgical radiographic examinations for the treatment with ossesintegrated implant give detailed information on the potential area for implantation. It should provide evaluation of morphology of the alveolar ridge, and quantity and quality of the available bone. The presence of lesions and anatomical landmarks are conditions and structures that may limit the placement of osseous implant. Important anatomical landmarks include the inferior alveolar canal and mental foramen in the mandible $(6,7)$.

Panoramic radiograph is a well-known and widely used radiographic image in preoperative planning for implant placement. It is considered to be the standard radiographic examination for implant treatment planning as it imparts a low radiation dose and gives the best radiographic survey (8). Yet they show a number of limitations; the images are two dimensional of a three dimensional structure. They fail to show the bucco-lingual dimension of bone. Therefore, they also fail to show spatial relationship between structures. However, the main disadvantage of panoramic images is the inherent distortion and magnification of the images. These ultimately limit dimensional accuracy in panoramic radiography (9).

CBCT provides cross sectional images that demonstrate the height and width of the alveolar bone providing a tool to evaluate the quantity through accurate measurement. In addition, CBCT allows assessment of the bone quality regarding density of the remaining bone (10).

CBCT also allows precise localization of adjacent anatomic structures including the nasal fossa and maxillary sinuses in the upper jaw and the inferior alveolar nerve canal in the mandible (11).

CBCT imaging, combined with special soft wares, provide a way to assess and plan the surgical and prosthetic part of implant therapy (12). Also images obtained from CBCT could be used for the fabrication of a surgical stent, without contact with patient, used for precise placement of the implant (10).

In this study, we aimed to assess the advantage of CBCT compared to digital panoramic radiography for treatment planning of mandibular dental implant size placement. 


\section{MATERIALS AND METHODS}

The clinical part of the study was formed after the approval of research ethics committee. Official consent was obtained from the patients. Each patient was informed about the study protocol and gave informed consent, medical and surgical history was taken from the patients.

A clinical trial was conducted on ten adult patients of both sexes (4 males and 6 females) having at least one missing mandibular molar or premolar tooth indicated for implant rehabilitation. The patients were selected from the Out Patient Clinic of the Oral and Maxillofacial Surgery Department, Faculty of Dentistry, Alexandria University.

The inclusion criteria of this study were; patients age ranging from 25-50 years, missing tooth or teeth in the posterior mandible, Patients free from any systemic condition interfering with implant insertion and sufficient bone width and height above the inferior alveolar canal in implant insertion. While the exclusion criteria were; pregnancy, local bone disease and systemic disease with oral repercussions.

\section{Implant system}

17 dentis system implants (Dentis s-clean tapered system, Woram-Dong, Dalseo-Gu, Daegu, Korea) were used in this study. This implant was an endosseos root form with resorbable blast media (RBM) surface treatment and tapered body with optimized thread, design and simplified conical prosthetic component.

It has an internal hex connection and having different lengths $(8,10,12$ and 14) and diameter (3.7, 4.1, 4.3 and 4.7).

\section{Pre-surgical preparation}

\section{a. Clinical examination:}

All patients underwent preoperative clinical examination; patients data were collected; name, gender and age, medical and dental histories were taken and the oral mucosa of the edentulous area was examined for color, texture, firmness and thickness.

\section{b. Preoperative radiographic examination:}

a. Initial implant planning digital panoramic radiograph was taken for every patient using an orthopantomograph (J. Morita Veraviewepocs 2D R100, Japan).

Using a special software (DCM software) the images magnification was corrected to give a 1:1 magnification images.

On the corrected panoramic radiograph the length of the implant used was determined directly from panoramic images with 1:1 magnification factor using a graduated implant scale with the same magnification factor. (Figure $1,4)$

The distance from the alveolar crest to the superior border of the inferior alveolar canal and mental foramen at the site of the proposed implant was measured (I dixel $\mathrm{v} 7.0$ software). (Figure 1)

According to that measurement, the length of implant used was determined. The length of the implant was at least $2 \mathrm{~mm}$ shorter than the measured distance on the radiograph to assure adequate safety margin as recommended by several authors (13-16).

The length and width of planned implant and bone measurement was recorded at this stage.

a. Immediately after initial planning Cone-Beam Computed Tomography (CBCT) (J Morita Veraviewepocs 3D R100, Japan.) were done to perform the implant site- specific assessment actual length and width of planned implant and measured the distance from the alveolar crest to the superior border of the inferior alveolar canal and the mental foramen at the site of the proposed implant (On Demand 3D Software). (Figure 2,5)
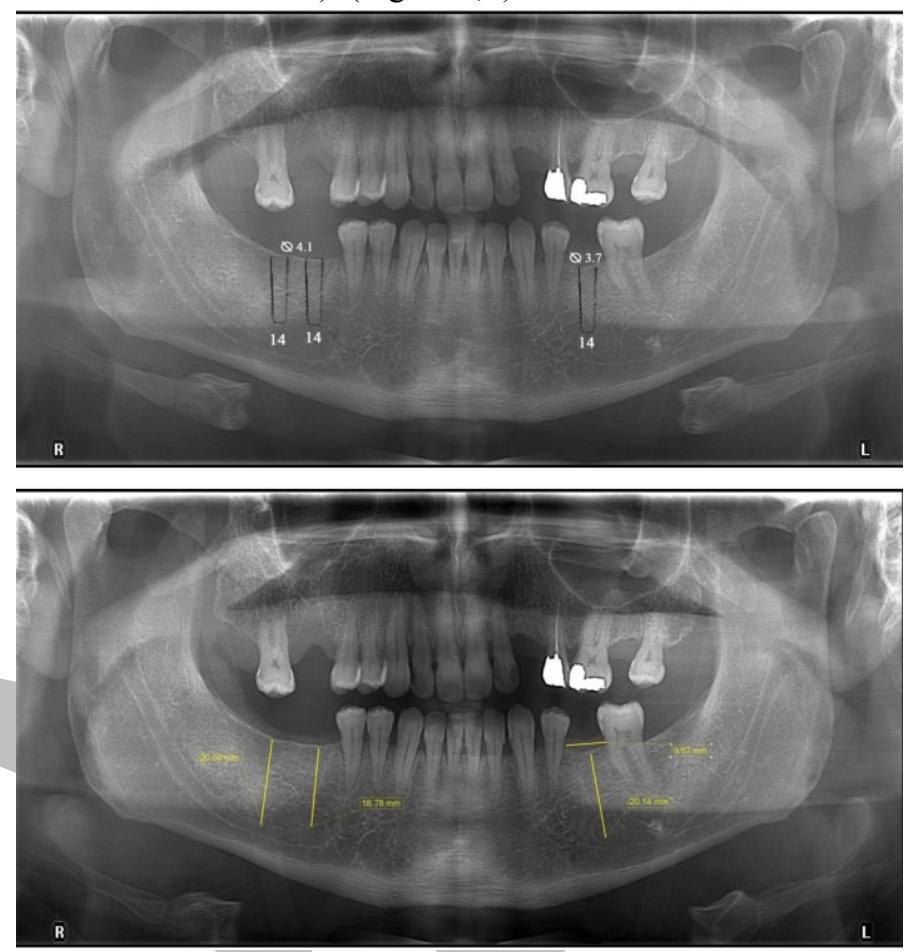

Figure (1): Preoperative planning on OPG radiographs for implant length and width and bone measurement from alveolar crest to inferior alveolar canal.

The implant dimensions and bone measurement were recorded at this stage.

Both initial and final records were tabulated and statistically compared.

b. Surgical phase:

- Anesthetic technique:

All surgical procedures were performed under local anesthesia, Articaine hydrochloride 4\% with 1:100 000 epinephrine (Septocaine, Inibsa Barcelona, Spain),by inferior alveolar and lingual nerve block with buccal infiltration opposite the implant site.

- Flap design:

Para-crestal incision was made along the edentulous area with one or two short releasing incisions. Full thickness mucoperiosteal flap was raised using a mucoperiosteal elevator.

- Preparation of the implant site:

- Initiation of osteotomy was performed in the central part of the alveolar bone, the initial marking or preparation of the implant site was done with pilot drill.

$\circ$ The pilot drill of $2.2 \mathrm{~mm}$ diameter was used. Drilling continued at the marked area to the planned depth which extended at least $2 \mathrm{~mm}$ shorter than the available bone height.

- The drilling parallelism was checked using paralleling pins.

- Standard drills of sequential diameters were used till reaching the planned final diameter.

- Implant placement:

- Using the information obtained in the preoperative planning, the implant was placed according to two stage surgical protocol. 
- The implant was inserted and screwed into the bone till the beveled shoulder reached the crest of the alveolar bone, and the cover screw was screwed into the fixture.

○ After surgery for implant placement, length and width of implants were recorded

- Suturing

The flap was returned into position and sutured by interrupted sutures using 4/0 braided polyglycolic acid suture.
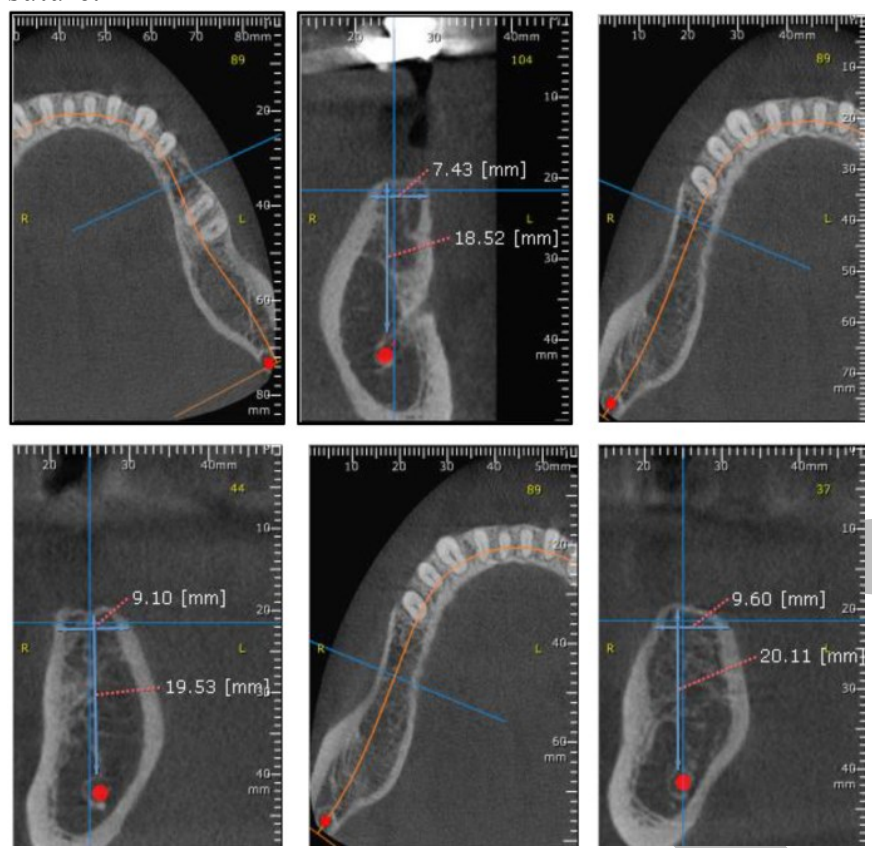

Figure (2): Preoperative planning on $\mathrm{CBCT}$ images for implant length and width and bone measurement from alveolar crest to inferior alveolar canal.

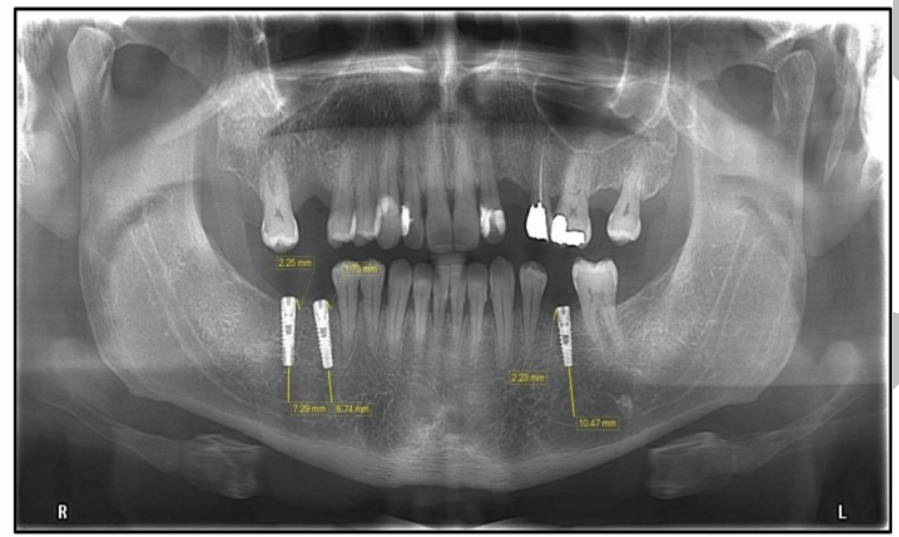

Figure (3): Postoperative OPG radiograph for suitability of implant dimension and bone marginal level and relation to anatomical land mark at 3 months.

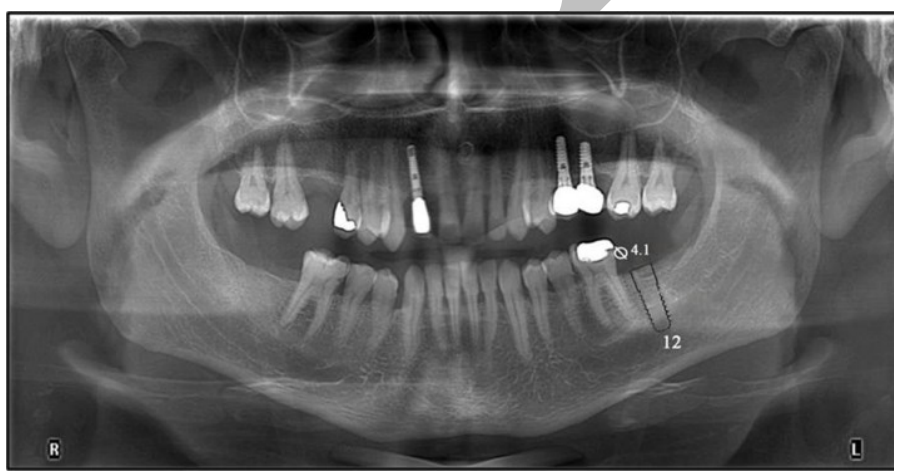

Figure (4): Preoperative planning on OPG radiograph for implant length and width.
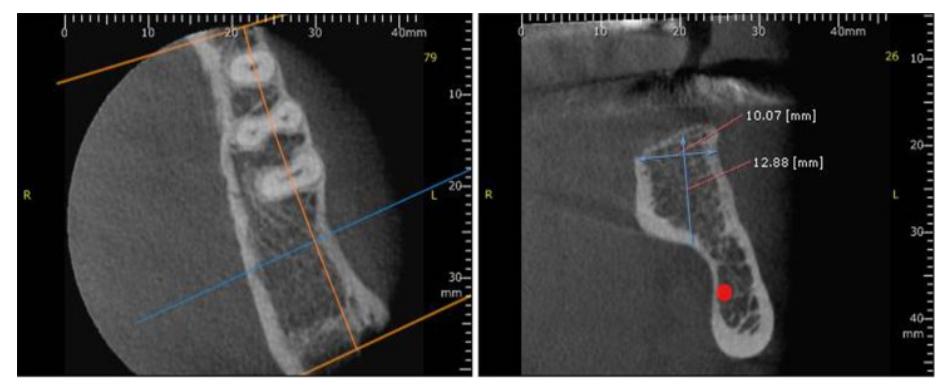

Figure (5): Preoperative planning on CBCT images for implant length and width.

c. Post-operative phase:

- Postoperative instructions and medications:

1) Pressure gauze pack was applied for one hour.

2) Apply extra oral ice packs on the cheek in the area of surgery intermittently every 10 minutes for 2 hours on the first day.

3) The preoperative antibiotic: Sulbactam $125 \mathrm{mg}$, ampicillin 250mg (Unasyn: Pfizer, New York, USA) was prescribed two times daily for five days.

4) Non-steroidal anti-inflammatory analgesic: Diclofenac potassium 50mg (Catafast, Novartis, Cairo, Egypt) was prescribed three times daily for three days.

5) Regular oral hygiene measures were resumed after 12 hours.

6) The mouth wash: Chlorohexidine Gluconate 0,1\%(Antiseptol, Kahira Pharma Co, Cairo, Egypt) was used 24 hours after surgery 3 times a day for 1 week.

\section{d. Follow-up phase:}

\section{- Clinical evaluation:}

All patients were evaluated immediately post-operatively and on intervals of 1 and 3 months, for presence of pain, swelling or infection using Visual Analogue scale (VAS) (17), gingival inflammation using the Loe and Silness Gingival index (18) on the $2^{\text {nd }}$ and $7^{\text {th }}$ post- operative days and the implant mobility was tested according to Mickney and Koth (19).

\section{- Radiographic evaluation}

Postoperative digital orthopantomogram (OPG) were made with the same machine and same exposure parameters used to obtain the preoperative radiographs. All the implants involved in this study were radiographed by OPG postoperatively at intervals of 1 and 3 months and examined to compare and reconfirm the preoperative records regarding: (Figure 3, 6)

$\circ$ The suitability of the implant dimensions.

o The marginal bone level.

$\circ$ The relations to surrounding structure.

\section{STATISTICAL ANALYSIS}

Frequency analysis will be used to describe the characteristics of both patients and implants, as well as the distribution of change between the different planning stage and the implants. The comparison between the implant dimensions, bone measurement with approximating anatomical landmark during preoperative planning stages (initial and final) and placed implant dimensions during surgery were tested using the paired t- test. The significance level will be set at $\mathrm{p}<0.05$.

\section{RESULTS}

Overall 17 implants were placed in the posterior mandible of ten patients. All examined cases were 4 males and 6 females with age ranging between 25-50 years, implants 
sites, length and width implants was measured by OPG and CBCT are presented in (Table 1).

The surgical procedure was generally well tolerated by all patients, none of the patients complained of postoperative altered sensation of the inferior lip which excludes injury to the neurovascular bundle.

Preoperative implant planning was based on panoramic radiography (initial), also preoperative implant planning was based on CBCT image (final) and the actual dimensions of implant placed during surgery.

The implant length at different planning and the actual of implant length during surgery presented in (Table 2). The mean initial planning was $12.5 \pm 1.70 \mathrm{~mm}$, final planning was $12.0 \pm 2.0 \mathrm{~mm}$ and during surgery $12.0 \pm 2.0 \mathrm{~mm}$.

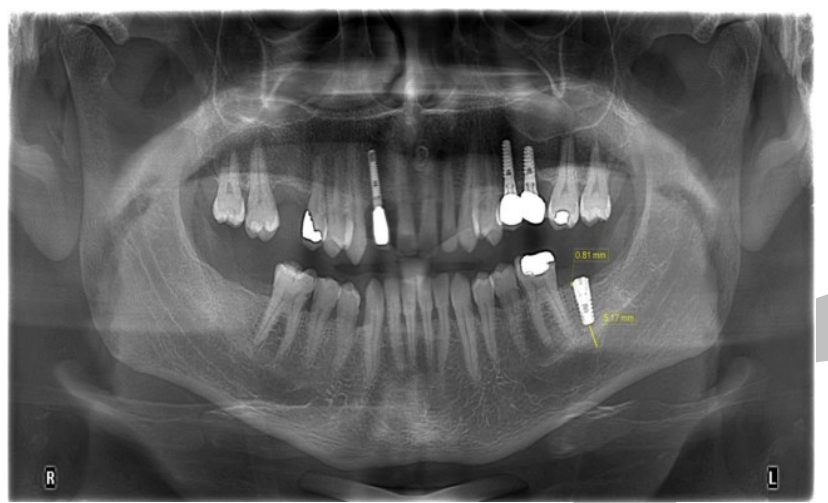

Figure (6): Postoperative OPG radiograph for suitability of implant dimension and bone marginal level and relation to anatomical land mark at 3 months.

The results showed statistical significant difference between initial and final planning $\mathrm{p} 1$, between initial and during surgery $\mathrm{p} 2$ and there was no statistical significant difference between final and during surgery $\mathrm{p} 3(\mathrm{p}>0.05)$.

Regarding length, the dimensions considered in final planning did not change in $100 \%$ of cases, in comparison with those found during surgery. In contrast, comparing the dimensions in initial planning to those found during surgery only $58.8 \%$ of cases remained unchanged, and the number of smaller dimensions was higher than the number of larger dimensions, the comparison between initial and final planning show a $41.2 \%$ rate of change.

The implant width at different planning and the actual of implant width placed during surgery presented in (Table 2). The mean initial planning was $4.02 \pm 0.19 \mathrm{~mm}$, final planning was $4.09 \pm 0.34 \mathrm{~mm}$ and during surgery $4.09 \pm 0.34 \mathrm{~mm}$.

The results showed no statistical significant difference between initial and final planning $\mathrm{p} 1$, between initial and during surgery $\mathrm{p} 2$ and between initial and during surgery $\mathrm{p} 3$ $(\mathrm{p}>0.05)$.

Regarding width, the dimensions considered in final planning did not change in $100 \%$ of cases, in contrast, comparing the dimensions in initial planning to those found during surgery only $64.7 \%$ of cases remained unchanged. However, the width decreased more frequently between initial and final planning and increased between final planning and surgery, the comparison between initial and final planning show a $35.3 \%$ rate of change.

The distribution bone measurement relation to anatomical landmark mandibular canal or mental foramen in implant site (Table 3). The mean initial planning was $16.25+3.03 \mathrm{~mm}$ and final planning $15.55 \pm .76 \mathrm{~mm}$, there was no statistical significant difference between initial and final planning ( $\mathrm{p}>0.05)$.

Postoperative clinical evaluation:

- Pain, swelling and/ or infection after surgery

All the patients experienced slight to mild pain at the surgical site. Four had slight pain and showed mild edema which subsided totally by the $2^{\text {nd }}$ post-operative day. Two other had mild pain and mild edema which also disappeared completely by the $2^{\text {nd }}$ post-operative day. Four patients experienced mild pain and moderate edema, which subsided totally by $5^{\text {th }}$ post-operative day. All patients continued the follow up period without any signs of infection, gingivitis, or peri-implantitis.

\section{- Gingival Index}

No signs of gingival inflammation were observed in all patients. (i.e. gingival index score was 0 ).

\section{- Implant mobility}

All over the evaluation period, none of the implants showed any signs of mobility (i.e. mobility score was 0 ).

Postoperative radiographic evaluation

- Suitability of the implant dimension:

All over the evaluation period, all the implants showed suitability of actual dimensions compared with preoperative planning.

\section{- Marginal bone level}

Bone loss was higher on the $3^{\text {rd }}$ months than 1 month. On the 1 month, the mean marginal bone level value was $0.51+0.73 \mathrm{~mm}$ with minimum recorded value of $0.1 \mathrm{~mm}$ and a maximum recorded value of $1.2 \mathrm{~mm}$. On the $3^{\text {rd }}$ months, the mean marginal bone level value was $1.20+0.65 \mathrm{~mm}$ with a minimum recorded value of $0.22 \mathrm{~mm}$ and a maximum recorded value of $2.25 \mathrm{~mm}$. The mean marginal bone level was statistically significant difference on the 1 month postoperatively compared with $3^{\text {rd }}$ months postoperative measurements $(\mathrm{p}=0.01)$.

\section{- Relation to surrounding structure}

The mean of relation to surrounding structure value was $3.86+2.34 \mathrm{~mm}$ with a minimum recorded value of $1.82 \mathrm{~mm}$ and a maximum recorded value of $10.47 \mathrm{~mm}$ at 1 and $3^{\text {rd }}$ months. The measurements showed accuracy of implant dimensions and relation with anatomical landmark like mandibular canal or mental foramen compared with preoperative planning

\section{DISCUSSION}

Implant planning is a result of combining the radiographic information of different types of images. This study assesses the advantage of CBCT compared to digital panoramic radiography for treatment planning of mandibular dental implant size.

The study shows that CBCT increases the accuracy of treatment planning in predicting implant length defined at surgery. The agreement in predicting the implant length was $58.8 \%$ in initial versus $100 \%$ in final planning, implant length unchanged after considering CBCT evaluation together with initial planning to conclude final planning, versus implant planning with CBCT evaluation and actual implant placement. This could be attributed to the tendency to overestimate the available bone for implant placement in panoramic radiographic, leading to great risk of injury to adjacent anatomic structures, like the inferior alveolar nerve or mental nerve $(20,21)$. 
The proportion of cases where implant width remained unchanged ranged from $64.7 \%$ (from initial to final planning) to $100 \%$ (from final planning to surgery). The limited benefit of using CBCT to detect implant width and the high levels of correct prediction at both initial $64.7 \%$ and final planning $100 \%$ stages must be viewed with some latitude, especially because cases with poor bone dimensions in which a CBCT exam would be essential were previously excluded from the study sample. In contrast, implant width was more frequently underestimated in final planning, compared to the actual width at implant placement (22).

Several factors have a negative impact on the reliability of panoramic radiographs. They are the $2 \mathrm{D}$ projection of a $3 \mathrm{D}$ volume, with inherent distortion and magnification. This might make planning more haphazard and less reliable. Oblique projection geometry also hampers good visualization. On the other hand, other study have reported that digital panoramic radiographs with $1: 1$ adjusted images are sufficiently accurate and reliable for evaluating the available bone height above the mandibular canal. Vazquez et al (23) found the implant length measurement was sufficiently reliable for evaluating the vertical magnification factor even when the patient's head position was not strictly standardized before exposure and when measurements were taken by observers with different skill levels and experience. The same author found similar results in another study on digital panoramic radiographs (24).

The aim of our study was to produce a realistic treatment plan for implant placement. Therefore, the observers were experienced implant surgeons instead of oral maxillofacial radiologists. Considering oral radiologists as observers was discarded due to their specific training on looking at the anatomy and diagnosis. A recent article on the accuracy of vertical height measurements on direct digital panoramic radiographs reported that an observer's experience had no clinically significant influence on the measurements even though, interestingly, a less-experienced observer had a lower distortion ratio than a more-experienced observer (24). Reporting all observers' data was very important: If two observers generally chose longer implants with $\mathrm{CBCT}$ and two generally chose shorter, in the overall combined results they could seem to cancel each other. Based on our results, we would recommend choosing a vertical safety margin in the posterior mandible in all cases. Similarly, Gerlach et al (25) suggested a vertical safety margin of at least $1.7 \mathrm{~mm}$ when CBCT images are used to select implants for the posterior mandible. This is close to the reported recommendations for OPG (15). This safety margin can avoid iatrogenic inferior alveolar nerve injuries following dental implant placement. However, Renton et al (26) found that a majority of idiopathic trigeminal neuropathies were found in patients who had undergone pre surgical 2D radiographs $(90 \%)$, while only $10 \%$ of the cases presented such neuropathies after pre surgical CBCT had been taken.

Additionally, the clinical procedure of combining radiographic information of different types of images (for example, OPG plus CBCT) often used for the planning of an implant site was followed in this study. An adequate determination of the bone height is recommended for avoiding the potential risks of intrusion of implants into vital anatomical structures including nerves, blood vessels, and impacted or supernumerary teeth (27). The buccolingual width and angulation of the available bone are the most important criteria for implant selection and success. According to Alsaadi et al (28) the implant diameter and location significantly affected the implant loss.

Table (1): Distribution of the studied cases according to demographic data

\begin{tabular}{|c|c|c|c|c|c|c|c|}
\hline \multirow{2}{*}{$\begin{array}{c}\text { Case } \\
\text { no. }\end{array}$} & \multirow[t]{2}{*}{ Sex } & \multirow{2}{*}{$\begin{array}{c}\text { Age } \\
\text { (Years) }\end{array}$} & \multirow{2}{*}{$\begin{array}{c}\text { Implant } \\
\text { Site }\end{array}$} & \multicolumn{2}{|c|}{ Implant Length } & \multicolumn{2}{|c|}{ Implant Width } \\
\hline & & & & OPG & 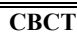 & 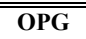 & 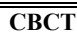 \\
\hline 1 & Male & 35 & $\begin{array}{l}\text { Mandibular } \\
\text { Right } 6 \\
\text { Mandibular } \\
\text { Right } 7 \\
\text { Mandibular } \\
\text { Left } 5\end{array}$ & $\begin{array}{l}14 \mathrm{~mm} \\
14 \mathrm{~mm} \\
14 \mathrm{~mm}\end{array}$ & $\begin{array}{l}14 \mathrm{~mm} \\
14 \mathrm{~mm} \\
12 \mathrm{~mm}\end{array}$ & $\begin{array}{l}4.1 \mathrm{~mm} \\
4.1 \mathrm{~mm} \\
3.7 \mathrm{~mm}\end{array}$ & $\begin{array}{l}4.1 \mathrm{~mm} \\
4.1 \mathrm{~mm} \\
3.7 \mathrm{~mm}\end{array}$ \\
\hline 2 & Female & $\overline{50}$ & $\begin{array}{l}\text { Mandibular } \\
\text { Left } 6 \\
\text { Mandibular } \\
\text { Right } 4 \\
\text { Mandibular } \\
\text { Right } 6\end{array}$ & $\begin{array}{l}12 \mathrm{~mm} \\
12 \mathrm{~mm} \\
14 \mathrm{~mm}\end{array}$ & $\begin{array}{l}12 \mathrm{~mm} \\
10 \mathrm{~mm} \\
12 \mathrm{~mm}\end{array}$ & $\begin{array}{l}4.1 \mathrm{~mm} \\
4.1 \mathrm{~mm} \\
4.1 \mathrm{~mm}\end{array}$ & $\begin{array}{l}4.3 \mathrm{~mm} \\
3.7 \mathrm{~mm} \\
4.1 \mathrm{~mm}\end{array}$ \\
\hline 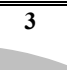 & Female & 50 & $\begin{array}{c}\text { Mandibular } \\
\text { Right } 7\end{array}$ & $12 \mathrm{~mm}$ & $10 \mathrm{~mm}$ & $4.1 \mathrm{~mm}$ & $3.7 \mathrm{~mm}$ \\
\hline 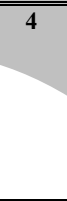 & Female & 25 & $\begin{array}{l}\text { Mandibular } \\
\text { Right } 4 \\
\text { Mandibular } \\
\text { Right } 6 \\
\text { Mandibular } \\
\text { Left } 6\end{array}$ & $\begin{array}{l}12 \mathrm{~mm} \\
14 \mathrm{~mm} \\
14 \mathrm{~mm}\end{array}$ & $\begin{array}{l}10 \mathrm{~mm} \\
14 \mathrm{~mm} \\
14 \mathrm{~mm}\end{array}$ & $\begin{array}{l}3.7 \mathrm{~mm} \\
4.1 \mathrm{~mm} \\
3.7 \mathrm{~mm}\end{array}$ & $\begin{array}{l}3.7 \mathrm{~mm} \\
4.8 \mathrm{~mm} \\
4.1 \mathrm{~mm}\end{array}$ \\
\hline 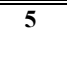 & Male & 40 & $\begin{array}{c}\text { Mandibular } \\
\text { Left } 7\end{array}$ & $12 \mathrm{~mm}$ & $10 \mathrm{~mm}$ & "4.1mm & "4.8mm \\
\hline "6 & Female & 50 & $\begin{array}{l}\text { Mandibular } \\
\text { Right } 6\end{array}$ & $8 \mathrm{~mm}$ & $8 \mathrm{~mm}$ & "4.1mm & "4.1mm \\
\hline 7 & Male & 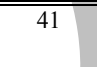 & $\begin{array}{l}\text { Mandibular } \\
\text { Left } 7\end{array}$ & $14 \mathrm{~mm}$ & $14 \mathrm{~mm}$ & "4.3mm & $4.3 \mathrm{~mm}$ \\
\hline 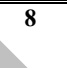 & Male & 36 & $\begin{array}{l}\text { Mandibular } \\
\text { Right } 6\end{array}$ & $12 \mathrm{~mm}$ & $12 \mathrm{~mm}$ & $4.1 \mathrm{~mm}$ & $\bar{~} 4.1 \mathrm{~mm}$ \\
\hline 9 & Female & 30 & $\begin{array}{c}\text { Mandibular } \\
\text { Right } 6\end{array}$ & $174 \mathrm{~mm}$ & $1212 \mathrm{~mm}$ & "4.1mm & $\bar{~} 4.1 \mathrm{~mm}$ \\
\hline$\overline{10}$ & Female & 25 & $\begin{array}{l}\text { Mandibular } \\
\text { Right } 5 \\
\text { Mandibular } \\
\text { Right } 6\end{array}$ & $\begin{array}{l}10 \mathrm{~mm} \\
12 \mathrm{~mm}\end{array}$ & $\begin{array}{l}10 \mathrm{~mm} \\
14 \mathrm{~mm}\end{array}$ & $\begin{array}{l}3.7 \mathrm{~mm} \\
4.1 \mathrm{~mm}\end{array}$ & $\begin{array}{l}3.7 \mathrm{~mm} \\
4.1 \mathrm{~mm}\end{array}$ \\
\hline
\end{tabular}

Table (2): Distribution of the studied cases according to implant length and width $(\mathrm{n}=17)$.

\begin{tabular}{|c|c|c|c|}
\hline & $\begin{array}{c}\text { Preoperative } \\
\text { planning on OPG } \\
\text { radiographs (Initial) }\end{array}$ & $\begin{array}{c}\text { Preoperative planning } \\
\text { on CBCT images } \\
\text { (Final) }\end{array}$ & during surgery \\
\hline $\begin{array}{c}\text { Implant Length } \\
(\mathrm{mm})\end{array}$ & & & \\
\hline Min. - Max. & $8.0-14.0$ & $8.0-14.0$ & $8.0-14.0$ \\
\hline Mean \pm SD & $12.59 \pm 1.70$ & $12.0 \pm 2.0$ & $12.0 \pm 2.0$ \\
\hline Median & 12.0 & 12.0 & 12.0 \\
\hline Significant & \multicolumn{3}{|c|}{$\mathrm{p}_{1}=0.056, \mathrm{p}_{2}=0.056, \mathrm{p}_{3}=1.000$} \\
\hline \multicolumn{4}{|l|}{$\begin{array}{c}\text { Implant Width } \\
(\mathrm{mm})\end{array}$} \\
\hline Min. - Max. & $3.70-4.30$ & $3.70-4.80$ & $3.70-4.80$ \\
\hline Mean $\pm \mathrm{SD}$ & $4.02 \pm 0.19$ & $4.09 \pm 0.34$ & $4.09 \pm 0.34$ \\
\hline Median & 4.10 & 4.10 & 4.10 \\
\hline Significant & \multicolumn{3}{|c|}{$\mathrm{p}_{1}=0.342, \mathrm{p}_{2}=0.342, \mathrm{p}_{3}=1.000$} \\
\hline
\end{tabular}

$\mathrm{p} 1: \mathrm{p}$ value for Paired t-test for comparing between Initial and final

$\mathrm{p} 2$ : $\mathrm{p}$ value for Paired t-test for comparing between Initial and during surgery $\mathrm{p} 3$ : $\mathrm{p}$ value for Paired t-test for comparing between final and during surgery 
Table (3): Distributions of the studied cases according to bone measurement relation to anatomical landmark in implant site.

\begin{tabular}{||l|c|c|c||}
\hline & $\begin{array}{c}\text { Preoperative } \\
\text { planning on OPG } \\
\text { radiographs } \\
\text { (Initial) }\end{array}$ & $\begin{array}{c}\text { Preoperative } \\
\text { planning on } \\
\text { CBCT image } \\
\text { (Final) }\end{array}$ & $\mathbf{p}$ \\
\hline $\begin{array}{l}\text { Bone measurement relation } \\
\text { to anatomical landmark in } \\
\text { implant site (mm) }\end{array}$ & $10.30-21.89$ & $9.94-20.11$ & \\
Min. - Max. & $16.25 \pm 3.03$ & $15.55 \pm 2.76$ & 0.075 \\
Mean \pm SD. & 15.60 & 15.72 & \\
Median & & & \\
\hline
\end{tabular}

Renouard and Nisand (29) conducted a review to evaluate the survival rate of dental implants related to their length and diameter. Concerning implant length, a relatively high number of published studies $(30,31)$ indicated an increased failure rate with short implants, which was associated with the surgeons' learning curves, routine surgical preparation (independent of the bone density), use of machined-surface implants, and placement in sites with poor bone density. Other publications $(32,33)$ reported that an adapted surgical preparation and the use of textured-surface implants have produced survival rates of short implants comparable with those obtained with longer ones. Considering the implant diameter, a few publications on wide-diameter implants have reported an increased failure rate. These publications have demonstrated that the implant survival rate and diameter showed no relationship $(32,33)$.

Other studies have reported on the variation in the pre surgical treatment planning after using conventional spiral tomography in addition to conventional radiographic exams. Frei et al (34) showed that conventional spiral tomography had a minor impact on the treatment planning of implant dimensions in posterior mandible cases. In their study, treatment plans with and without spiral tomograms were identical in 74 of $77(96.1 \%)$ implant sites. In only $3.9 \%$ of these cases, implant diameters had changed, while no changes occurred in the implant length after the use of tomograms. In another study, the variation in implant dimension was not affected by the location of edentulous areas after using conventional spiral tomography (35).

Finally, the measurements had acceptable accuracy and reproducibility when a software-based calibrated measurement tool was used confirming that either OPG or CBCT can be reliably utilized to determine the preoperative implant width. However, care should be taken when using OPG-based preoperative planning of implants with a predisposition to select longer implant lengths in a posterior area and therefore, a more risky location. In addition, CBCT can allow observers to plan implant surgery with an improved subjective image quality and higher surgical confidence.

\section{CONCLUSION}

In conclusion, there were significant changes in the length of the selected implants in initial planning versus that of implants placed at surgery, suggesting that CBCT improves the ability to predict the actual implant length, thus reducing inaccuracy in the surgical planning of dental implants.

\section{CONFLICT OF INTEREST}

The authors declare that they have no conflicts of interest.

\section{REFERENCES}

1. Holst S, Blatz M.B., Eitner S. Precision for Computer Guided Implant Placement: Using 3D Planning Software and fixed Intraoral Reference Points. J Oral Maxillofac Surg 2007; 65: 393-9.

2. Harris D, Buser D, Dula K, Grondahl K, Haris D, Jacobs R, et al. E.A.O. guidelines for the use of diagnostic imaging in implant dentistry. A consensus workshop organized by the European Association for Osseointegration in Trinity College Dublin. Clin Oral Implants Res 2002; 13: 566-70.

3. Tyndall DA, Price JB, Tetradis S, Ganz SD, Hildebolt C, ScarfeWC. Position statement of the American Academy of Oral and Maxillofacial Radiology on selection criteria for the use of radiology in dental implantology with emphasis on cone beam computed tomography. Oral Surg Oral Med Oral Pathol Oral Radiol 2012; 113: 817-26.

4. Engelman MJ, Sorensen JA, Moy P. Optimum placement of osseointegrated implants. J Prothet Dent. 1988; 59: 467-73.

5. DaSilva JD, Schnitman PA, Wohrle PS, Wang HN. Influence of site on implant survival: 6-year results. J Dent Res 1992; 71: 56-59.

6. Tyndall AA, Brooks SL. Selection criteria for dental implant siteimaging: a position paper of the American Academy of Oral and Maxillofacial radiology. Oral Surg Oral Med Oral Pathol Oral Radiol Endod 2000; 89: 630-7.

7. Beason RC, Brooks SL. Preoperative implant site assessment in southeast Michigan. J Dent Res 2001; 80: 137-40.

8. Dula K, Mini R, van der Stelt PF, Buser D. The radiographic assessment of implant patients: decision-making criteria. Int J Oral Maxillofac Implants 2001; 16: 80-9.

9. Stramotas S, Geenty JP, Petocz P, Darendeliler MA. Accuracy of linear and angular measurements on panoramic radiographs taken at various positions in vitro. Eur J Orthod 2002; 24: 43-52.

10. Quereshy FA, Savell TA, Palomo JM. Applications of cone beam computed tomography in the practice of oral and maxillofacial surgery. J Oral Maxillofac Surg 2008; 66: 791-6.

11. Miracle AC, Mukheji SK. Conebeam CT of the head and neck, part 1: physical principles. AJNR Am J Neuroradiol 2009; 30: 1088-96.

12. White SC, Pharoah MJ, Frederiksen NL. Computed Tomography. In: White SC, Pharoah MJ (eds). Oral Radiology Principles and interpretation. St. Louis, Missouri, USA: Mosby Elsevier, 2008. 207-12.

13. Bartling R, Freeman K, Kraut RA. The incidence of altered sensation of the mental nerve after mandibular implant placement. J Oral maxillofac Surg 1999; 57:1408-11.

14. Greenstein G, Tarnow D. The mental foramen and nerve: clinical and anatomical s factors related to dental implant placement. J Periodontol 2006; 77: 1933-7.

15. Vazquez L, Saulacic N, Belser US. Bernard J. Efficacy of panoramic radiographs in the preoperative planning of posterior mandibular implants: a prospective clinical study of 1527 consecutively treated patients. Clin Oral Implants Res 2008; 19: 81-5.

16. Kraut RA. Chahal O. Management of patients with trigeminal nerve injuries after mandibular implant placement. J Am Dent Assoc 2002; 133: 1351-4.

17. Boonstra AM, Schiphorst Preuper HR, Reneman MF, Posthumus JB, Stewart RE. Reliability and validity of the visual analogue scale for disability in patients with chronic musculoskeletal pain. Int J Rehabil Res 2008; 31: 165-9. 
18. McClanahan SF, Bartizek RD, Biesbrock AR. Identification and consequences of distinct Löe-Silness gingival index examiner styles for the clinical assessment of gingivitis. $\mathbf{J}$ Periodontol 2001; 72: 383-92.

19. Steflik D, Koth DL, Robinson F, McKinney R, Davis B, Morris $C$, et al. Prospective investigation of the singlecrystal sapphire endosteal dental implant in humans: Tenyear results. J Oral Implantol 1995; 21: 8-18.

20. Batenburg RH, Stellingsma K, Raghoebar GM, Vissink A. Bone height measurements on panoramic radiographs: the effect of shape and position of edentulous mandibles. Oral Surg Oral Med Oral Pathol Oral Radiol Endod 1997; 84: 430-5.

21. Choi YG, Kim YK, Eckert SE, Shim CH. Cross-sectional study of the factors that influence radiographic magnification of implant diameter and length. Int J Oral Maxillofac Implants 2004; 19: 594-6.

22. White SC, Heslop EW, Hollender LG, Mosier KM, Ruprecht A, Shrout MK. Parameters of radiologic care: An official report of the American Academy of Oral and Maxillofacial Radiology. Oral Surg Oral Med Oral Pathol Oral Radiol Endod 2001; 91: 498-511.

23. Vazquez L, Nizamaldin Y, Combescure C, Nedir R, Bischof M, Dohan Ehrenfest DM, et al. Accuracy of vertical height measurements on direct digital panoramic radiographs using posterior mandibular implants and metal balls as reference objects. Dentomaxillofac Radiol 2013; 42:20110429.

24. Vazques L, Nizam Al Din Y, Christoph Belser U, Comescure C, Bernard JP.Reliability of the vertical magnification factor on panoramic radiographs: clinical implications for posterior mandibular implants. Clin Oral Implants Res 2011; 22: 1420-5.

25. Gerlach NL, Meijer GJ, Maal TJ, Mulder J, Rangel FA, Borstlap WA, et al. Reproducibility of 3 different tracing methods based on cone beam computed tomography in determining the anatomical position of the mandibular canal. J Oral Maxillofac Surg 2010; 68: 811-7.

26. Renton T, Dawood A, Shah A, Searson L, Yilmaz Z. Postimplant neuropathy of the trigeminal nerve. A case series. Br Dent J 2012; 212: E17.

27. Benavides E, Rios HF, Ganz SD, An CH, Resnik R, Reardon GT, et al. Use of cone beam computed tomography in implant dentistry: the International Congress of Oral Implantologists consensus report. Implant Dent 2012; 21 : 78-86.

28. Alsaadi G, Quirynen M, Michiles K, Teughels W, Komárek A, van Steenberghe D. Impact of local and systemic factors on the incidence of failures up to abutment connection with modified surface oral implants. J Clin Periodontol 2008; 35 : 51-7.

29. Renouard F, Nisand D. Impact of implant length and diameter on survival rates. Clin Oral Implants Res 2006; 17(Suppl 2): 35-51.

30. Herrmann I, Lekholm U, Holm S, Kultje C. Evaluation of patient and implant characteristics as potential prognostic factors for oral implant failures. Int $\mathrm{J}$ Oral Maxillofac Implants 2005; 20: 220-30.

31. Weng D, Jacobson Z, Tarnow D, Hürzeler MB, Faehn O, Sanavi $F$, et al. A prospective multicenter clinical trial of $3 i$ machined-surface implants: results after 6 years of followup. Int J Oral Maxillofac Implants 2003; 18: 417-23.
32. Lemmerman KJ, Lemmerman NE. Osseointegrated dental implants in private practice: a long-term case series study. $\mathrm{J}$ Periodontol 2005; 76: 310-9.

33. Romeo E, Lops D, Margutti E, Ghisolfi M, Chiapasco M, Vogel G. Long-term survival and success of oral implants in the treatment of full and partial arches: a 7-year prospective study with the ITI dental implant system. Int J Oral Maxillofac Implants 2004; 19: 247-59.

34. Frei C, Buser D, Dula K. Study on the necessity for crosssection imaging of the posterior mandible for treatment planning of standard cases in implant dentistry. Clin Oral Implants Res 2004; 15: 490-7.

35. Diniz AF, Mendonça EF, Leles CR, Guilherme AS, Cavalcante MP, Silva MA. Changes in the pre-surgical treatment planning using conventional spiral tomography. Clin Oral Implants Res 2008; 19: 249-53. 